\title{
Negros y milicianos pardos en Piura durante las Cortes de Cádiz (1812-1813)
}

Recibido: 19/09/2016

Aprobado: 24/10/2016

César Espinoza Claudio*

Universidad Nacional Mayor de San Marcos

< cespinozac@unmsm.edu.pe >

\section{RESUMEN}

Los Borbones van a imponer una variedad de transformaciones de las diferenciaciones y categorías culturales institucionalizadas en la provincia de Piura. El estudio de estos cambios políticos a principios del siglo XIX es muy escaso. En los ensayos que publicamos en 2013 y 2014 verificamos que al interior de este microespacio regional de la costa norte del virreinato del Perú se había producido una redefinición de las fronteras culturales entre las agrupaciones poblacionales que ocupaban los valles de La Chira y el Piura. En esta ocasión describimos y analizamos la actuación de un negro liberto en Sechura y una página de la historia de los milicianos pardos en la ciudad de Piura a comienzos del siglo XIX.

Palabras Clave: Piura, Borbones, Pardos, milicianos, cultura política.

\section{Black Men and 'Pardo' Militiamen in Piura during Cadiz Courts (1812-1813)}

\begin{abstract}
The Bourbons imposed a variety of transformations related to cultural differentiations and categories that were institutionalized in Piura's province. There are few studies of these political changes in the early nineteenth century. In our 2013 and 2014 published papers, we verified that within this regional micro-space in northern coast of Peru's viceroyalty there had been a redefinition of cultural boundaries between population groups that occupied the valleys of La Chira and Piura. On this occasion, we describe and analyze the performance of a 'negro liberto' (black freedman) in Sechura and also a page in the history of the 'pardo' militiamen (triple-breed, Amerindian/white/black men) confronted with liberal Creoles in Piura's city during the early nineteenth century.
\end{abstract}

KeYwords: Piura, Bourbons, Pardos, Militiamen, Political Culture.

* Este trabajo es la segunda parte revisada y reactualizada del Informe Final del Proyecto N ${ }^{\circ}$ 151501011, VRIP-IIHS, Facultad de Ciencias Sociales, UNMSM, Perú, 2015. 


\section{Introducción}

A comienzos del siglo XIX la provincia de Piura se militariza ante la presencia de embarcaciones inglesas que se estacionan temporalmente en Tumbes y Payta. De igual forma, el virrey Abascal organiza varios batallones de milicianos que van a instalarse en la sierra de Ayabaca y Huancabamba para asegurar los territorios de Jaén de Bracamoros y de Loja, lugares estratégicos y de comunicación con el río Amazonas que será utilizado por los colonos portugueses para ampliar su frontera mercantil hasta Moyobamba (Carcelén y Maldonado 2013 y Waldemar Espinoza 2014).

Esta singular situación política permitirá la formación de un espacio para que un sector de los afrodescendientes de Piura se integren a las milicias de pardos formándose así un subsector poblacional que buscará afirmarse en un nuevo status social con la llegada de la Constitución de Cádiz en 1812 y establecerse en Piura la utilización de nuevas categorías sociales como la de "ciudadanos" y de "espańoles" por las autoridades y las gentes del campo y de la ciudad. ${ }^{2}$

A principios del siglo XIX, en la América española se percibe una serie de transformaciones que generalmente se interpretan dentro del contexto más amplio de la transición de una sociedad de antiguo régimen a un nuevo orden absolutista.

Con la llegada del siglo XIX, los Borbones intensificaron sus políticas en varias esferas de la vida económica, social y política de las regiones que integran el virreinato del Perú. La población afrodescendiente en Piura es pequeña pero dinámica; sus gentes buscan reinstalarse al interior de los barrios que se han organizado en la ciudad de San Miguel de Piura. Esta población tiene acceso a las letras, a la escritura y maneja una poderosa memoria oral para afirmar sus identidades culturales que transitaran de la organización en castas a la de vecinos y de ciudadanos que impone gradualmente la Constitución de Cádiz desde 1812 (O’Phelan 2012: 189-204). ${ }^{3}$

Estas transformaciones en las diferenciaciones y categorías culturales institucionalizadas que se habían im-

1 Los estudios sobre los milicianos y los ejércitos en Hispanoamérica es vasto y compleja. Para este ensayo hemos consultado a Kuethe y Marchena 2005; Macchi 2012; Maldonado y Carcelén 2013; Marchena 1992; Morea 2005; Conde y Alarcón 2014; Hunefeldt 1979.

2 Sobre el contexto político y el uso de estas categorías del mundo social moderno puede consultarse a C. Aljovin 2006 y Javier Fernández S. 2016.

3 Para la experiencia histórica y política de Piura puede consultarse Espinoza Claudio 2016: 117-138. puesto a la población afrodescendiente van a redefinir los patrones de conducta y de comportamiento entre los afrodescendientes y con la elite dominante regional. Surgen de esta forma individuos afrodescendientes que disponen de un capital monetario y que se orientan al comercio local e interregional y que mediante procesos judiciales buscan conservar su nuevo status social apoyándose en las normas gaditanas. Otros se dedican no solo a la acumulación de dinero sino también a la actividad política de resistencia social a la dominación de las autoridades españolas buscando agruparse con otros libertos e impulsando paralelamente nuevas actividades mercantiles y buscando emparejarse con mujeres de piel más clara y apellidos no africanos. Se vive por tanto, un tiempo de transición gradual en la que gradualmente se van estableciendo nuevas categorías normativas y nuevas prácticas políticas cotidianas. (Espinoza Claudio 2016).

\section{Fronteras culturales y posicionamiento social de las milicias pardas en Piura}

Para el virrey del Perú, el puerto de Payta mantiene una situación estratégica para la comunicación marítima con Guayaquil y Panamá. El peligro de la invasión británica por el mar era latente y de igual forma la introducción de fuerzas portuguesas por Jaén de Bracamoros, Loja y Moyobamba. En efecto, estas últimas poblaciones estaban próximas a la sierra de Ayabaca, Huancabamba y Cajamarca, lugares limítrofes a la ciudad de SM de Piura y de Trujillo, las cuales formaban parte de una de las regiones de la América española con una significativa presencia de contingentes militares (W. Espinoza 2014).

Para comienzos del siglo XIX, un sector importante de las milicias de la Intendencia de Trujillo estaba integrada por unidades de pardos, es decir, de afrodescendientes, o milicias de color.

La toma de La Habana (Cuba) por los ingleses en 1762, había acelerado la reorganización del sistema defensivo en el Perú, y en Payta se empezó más adelante a construir un pequeńo "fuerte" armado, edificando todavía pequeńos almacenes para conservar armas y pólvora, y reforzando los sistemas de vigilancia con indígenas de Sechura y Colán para observar el movimiento de toda clase de embarcaciones que bajaban de Guayaquil y Tumbes. En Amotape y el valle de La Chira se organizaron los batallones de Dragones que estarían conducidos por los dueños de las haciendas y estancias ganaderas. 
Con la presencia de naves y embarcaciones británicas en Tumbes y Payta en 1805 aumentó la importancia de la formación de estos batallones de milicias disciplinadas integradas por jóvenes afrodescendientes. No conocemos todavía si la mayor parte de estas milicias portadoras de atribuciones étnico-raciales estuvieron integradas por gente nacida en Piura procedían de Lambayeque o Trujillo. Lo cierto es que el reclutamiento de estos individuos de color también produjo serios problemas familiares y de amores incontenibles entre negros y mujeres blancas criollas. Algunos procesos judiciales revisados muestran entonces como las milicias en Piura ya están divididas en batallones integrados por gente blanca y otros llamados pardos, es necesario advertir que no todos eran negros (Espinoza Claudio, 2014).

A comienzos del siglo XIX, el valle de La Chira en conjunto está ocupada y vigilada por batallones de milicianos pardos y morenos. Así, en Máncora y Pariñas los trabajadores afrodescendientes que laboraban en la preparación de la brea ya no están registrados en estas haciendas. Es probable que los varones se encuentren incorporados a las milicias de seguridad provincial, otros trasladados a la ciudad-puerto de Payta, y el resto a la ciudad de SM de Piura.

Las unidades de los pardos y sus oficiales están dispersos entre Tumbes, Amotape, Querecotillo y La Punta. En el valle de La Chira, estas milicias sirven como una fuerza política favorable a los dueños de las haciendas; así, otros pequeños poblados rurales como La Huaca, Amotape y La Punta solo servirán como lugares de residencia temporal de los campesinos labradores, de los crianderos de ganado caprino, de los colonos y yanaconas y de un sector de la población afrodescendiente. Son microurbes que estan sujetas a la lógica económica de las haciendas que demandaban fuerza de trabajo para sus tareas de siembra y cosecha, de crianza, engorde y la matanza del ganado caprino y ovino y el suministro de sebos y grasas para las tinas instaladas a orillas del río La Chira y el Piura.

$\mathrm{Al}$ interior de estas unidades semiurbanas funciona un sistema de autoridades y de representantes que actúan subordinados al Subdelegado y al cura-vicario de Piura. Entre sus prácticas habituales de reproducción del sistema colonial destaca la lectura de los bandos virreinales, la realización de las fiestas reales y religiosas, la vigilancia del comercio local, y también, la de asegurar el movimiento normal de los viajeros que llegaban desde Trujillo-Piura o a la inversa, desde Tumbes y la sierra de Loja-Cuenca. Es a partir de estos poblados que se incre- menta la enseñanza de la escritura y la lectura con preceptores que van a ser contratados por las autoridades locales. Pero la enseñanza no solo se limita a las letras sino también al respeto de símbolos como las banderas y los pendones, el sonido diurno y nocturno de las campanas, la higiene corporal y el trabajo colectivo para conservar el perímetro urbano de estas pequeñas urbes que ańos después transitaran de caseríos a villas, y luego a capitales de distritos, e incluso a capital de provincia como ocurrió con La Punta de Tillopaira que será renombrada durante la república como la ciudad de Sullana. Lo sustantivo de esta experiencia en la que participará la población multiétnica es que se mantendrá el sistema de autoridades y de representantes de los vecinos y la construcción de pequeñas plazas como espacios públicos y políticos en estas primeras décadas del siglo XIX.

De esta forma, en cada uno de estos poblados se levantó una capilla, un local de reuniones de las autoridades, una plaza pública y empiezan a formarse los barrios por las familias de labradores y de vaqueros estancieros. En su perímetro urbano, todavía no fijo, se asientan temporalmente las familias indígenas, mestizas y de negros esclavos y libertos para dar forma a una institución, la ciudad y su instancia de autogobierno que se fortalecerá con la llegada de la República.

$\mathrm{La}$ institucionalidad de la republica de indios y sus principios de organización social pareció permanecer en Piura. Los cacicazgos ya no funcionan pero los clanes parentales que los rodeaban ocupan ahora los cargos de alcaldes y de regidores del Cabildo de Indios. Estos representantes oficiales de las comunidades indígenas conservan la estratificación social interna, los alcaldes y justicias de los indios están subordinados ahora al Subdelegado de Piura. Los bandos reales que anuncian los asuntos de la provincia o del virreinato serán pregonados en el pueblo. Y si se trata de asuntos judiciales con afrodescendientes se comunicará inmediatamente a la autoridad provincial o a los alcaldes del Ayuntamiento de SM de Piura.

\section{La resistencia socio-legal de un afrodescendiente que viaja desterrado de Cańete a Lima, Guayaquil, Piura y Sechura, en el contexto político de la implementación de las Cortes de Cádiz en el Perú, 1812 y 1813}

En el invierno de1812, Manuel Encarnación Baquijano (MEB), negro criollo y esclavo, es procesado por las 
autoridades políticas y judiciales de Piura por cometer el delito de homicidio contra José Rumiche, un indio habitante del pueblo de Sechura. ${ }^{4}$ La reconstrucción y lectura de este acontecimiento nos permitirá conocer cómo se movilizaron las autoridades y las estructuras de dominación de la Subdelegación sobre las poblaciones indígenas y de color. La separación o límites entre las culturas y repúblicas de corte austriaco todavía subsistían y las manipulaban los borbones para lograr el control interno de individuos y grupos humanos. En efecto, desde el pueblo de Sechura, en 09.07.1812, el alcalde Chunga y los regidores Lorenzo Purizaga, Manuel Reyes y Francisco Chapilliquen, comunican al subdelegado de Piura, don Juan Ascencio de Monasterio, el asesinato de un indígena por un negro esclavo de propiedad de don Diego Godos. En un primer escrito se precisa que este acto fue realizado a las cuatro de la tarde y que MEB utilizó un cuchillo que lo introdujo en la tetilla al indio Juan Rumiche. Se anota que este acto fue observado por otros indios del pueblo: Narciso Rumiche, Vicente Eche, Isidoro Tumí, Antonillo Eche, Martín Eche, José Panta y Juan Vite. Concluye la primera parte de este informe señalando que fueron las autoridades ("ministros") de este pueblo los que organizaron el seguimiento y la captura del negro, recuperando también el arma utilizado y el caballo que montó para internarse en los médanos de Sechura.

En efecto, con la finalidad de recoger información directa, el subdelegado de Piura encargó a don Antonio Quintanilla, residente en Sechura, la comisión de recibir los testimonios orales de varios testigos. Esta acción se cumplió en 11.07.812, estando presentes los dos alcaldes y el regidor don Julián Lara. El primero en presentarse es don Narciso Rumiche quien declaró ser originario de Sechura, de casta chola, edad 30 años y hombre recién casado. Este declara que el día de los sucesos estuvo en el sitio llamado la "lagartera, y que se encontraba en la "caxa" del río pescando y que terminada esta tarea se dirigió a su rancho". En el camino vio a un negro estacionado al pie de un pequeño árbol y también que el finado Rumiche y otro grupo de indios buscaban un jumento y que se acercaron al negro cimarrón que estaba vestido con un poncho. No pasó mucho tiempo cuando escuchó un vocerío y gritos de que Rumiche había recibido una puñalada y que entonces empezó una persecución por más de dos leguas. Así vio

4 ARP, 1812, Intendencia, Causas Criminales, legajo 67, Expediente 1354,35 fs. como el negro montado en su caballo fugaba por los médanos pero con apoyo de otras gentes lo cercaron en un sitio abundante de "chilcos" prendiéndole fuego. Es en este momento que con la ayuda de Manuel Baca y Lorenzo Purizaga y los indios que acudieron con sus lampas al negro solo le quedó rendirse (f.3).

A continuación se presentan otros testigos como Vicente Eche, Antonillo Eche, Martin Eche, Juan Vite y José Panta, quienes repiten esta información y agregan otros datos adicionales como que el negro les había informado que viajaba rumbo a Lambayeque, que la herida medía tres dedos de largo, que el poncho que usaba era de color aplomado o que el sitio de la "lagartera" se encontraba ubicado a una legua del pueblo de Sechura. ${ }^{5}$

En 14.07.1812, el Subdelegado Monasterio ordenó que el negro ME Baquíjano permanezca en el "infiernillo" de la Real Cárcel de Piura bajo el cuidado del carcelero Esteban Azaña.

Nuevamente, en 16.07 , se recoge el testimonio y la memoria de vida de Manuel Encarnación Baquíjano. Ahora preguntado por sus generales de ley, Manuel Encarnación declara ser natural de la hacienda La Guaca, provincia de Cañete, propiedad de los herederos del finado don Domingo Ramírez de Arellano, vecino de la ciudad de Lima; agrega que tiene 30 años, de casta negro, y que desempeñó el oficio de gañán, peón de caña y de lampero. Manifiesta que es hombre casado con Manuela Sacramento, de casta negra y esclava, natural de la hacienda mencionada $(f .7 v)$. Confiesa que se encuentra preso por la muerte de un cholo de Sechura, hecho que se produjo a una legua de este pueblo un miércoles del 08.07, como a las cuatro de la tarde. Añade que en este caso se encontraba en una situación especial: "porque yendo el confesante de fuga que había hecho de la casa-tina que tiene en San Miguel de Piura el alcalde y regidor don Diego Manuel Farfán de los Godos, aquí se le tenía preso con una platina de fierro y que se fugó con otros esclavos presos en esa tina". Recuerda además, que en esa ocasión estuvieron Juan Barra, negro criollo y esclavo del cura y vicario de Catacaos, don Tomas Dieguez, y Manuel Barreto, negro bozal, quienes practicaron un forado en la pared de la casa-tina para luego escaparse a los médanos desérticos. Precisa que realizada la fuga cada uno avanzó por direcciones diferentes y que así avanzó durante el día y ocurrió

5 Sobre el pueblo indígena de Sechura han escrito Lorenzo Huertas 1995 y 2000, y Alejandro Diez Hurtado 1994. 
que cuando trataba de ocultarse de sus perseguidores y de las gentes del pueblo de Sechura, se encontró y avisó con un silbido al tal Rumiche a quien le alcanzó una moneda de un real de plata para que le enseñara el camino al Lambayeque. Fue por tanto, que en este primer momento de este encuentro que Rumiche le avisa que él también iba a Lambayeque, y ocurrió que cuando recogía el cabestro de su caballo, este cholo Rumiche realizó el intento de detenerlo y que allí se cogieron a la fuerza de las manos y ocurrió que en este forcejeo se le introdujo el cuchillo que portaba en el pecho de Rumiche. Esta acción entonces fue vista por otro grupo de indígenas que se acercaron, y ante el peligro de ser linchado, optó por salir montado en su caballo y portando su cuchillo nuevamente a los médanos desérticos. Manuel Encarnación añade que avanzó con mucho miedo un poco más de media legua, y que después se metió a unos arbustos llamados "chilcos" hasta que llegó un hombre blanco y se entregó preso. A continuación lo llevaron al pueblo de Sechura y realizó una primera confesión ante el cura local quien ordenó que lo pusieran en el cepo y la cárcel de este pueblo.

Fue así que, cuando pensaba que por fin tendría un momento de paz, ocurrió una grave situación contra su persona, pues en la noche los indios encolerizados se reunieron y le descargaron sobre su cuerpo muchos golpes con palos y piedras, y que incluso llegaron a colgarlo de una viga. Fue solo con la presencia y la intervención oportuna del cura que pudo cortarse estos castigos para luego llevarlo a su casa, donde permaneció dos días para recuperarse y ser trasladado a la ciudad de Piura en 13.07, llegando a la real cárcel a las cinco y media de la tarde (f.9).

Otro asunto que recuerda y declara Manuel Encarnación Baquíjano es que días antes se había fugado de una casa-tina de la ciudad de San Miguel de Piura como a las doce de la noche, y que en esa ocasión había comprado el cuchillo en este lugar a un negro llamado Miguel por el precio de tres reales en moneda de plata. Agrega que el propósito de su fuga de la casa-tina fue la de viajar a la ciudad de Lima, pues había llegado a la ciudad de SM de Piura procedente de la ciudad de Guayaquil por mar, usando una pequeńa embarcación de un payteño a quien le pagó seis pesos por este viaje (f.9v).

Sobre este asunto MEB añade nueva información. Explica que en la ciudad de Guayaquil estuvo alojado en la casa de don Bernardo Roca en calidad de deste- rrado por su amo y dueño de la hacienda La Guaca junto a otros tres compańeros esclavos cuyos nombres son: Pedro, Lucas Evangelista y Juan Pablo Baquíjano, todos negros "por el delito de haberse alzado distintas veces en la dicha Hacienda contra el administrador y mayoral de ella, nombrado el primero don Jorge Fernández, presbítero, y el segundo, José Ambrocio Baquíjano, negro esclavo de la propia hacienda, de cuyos alzamientos pusieron al confesante y sus compañeros que ha sido ellos los principales cabezas de motín. Que los dichos compañeros...en la hacienda de Balaos, propia de don Bernardo, y que el confesante quedó en la casa de este para poner agua en ella, y pagar jornal, y lo estuvo haciendo, hasta que se embarcó para Payta con ánimo de seguir para Lima y no pudo lograrlo porque fue capturado por la justicia y que luego lo pusieron en la casa-tina con otro negro nombrado Pedro Rayo y Flores, esclavo de la hacienda de Gualcará, del pueblo de Cañete, el cual se lo remitieron a su amo, y quedó el solo en la prisión" (f.10). ${ }^{6}$

En otra parte del interrogatorio que se le practica, se le pregunta por el número de veces que estuvo preso antes de 1812 y en qué lugares y cárceles estuvo encerrado, así como los motivos para estar encarcelado. Respondió ME Baquíjano que en la hacienda de la Guaca estuvo preso tres veces junto a "Carcancas" por motivo de faltar a sus obligaciones. Después, en la panadería de la Acequia Alta una vez. En este caso señala que su dueño fue don Diego Farfán de los Godos, y que en esa oportunidad se le acusó del "delito de sublevación en la hacienda" y que de allí lo desterraron a la ciudad de Guayaquil. Precisa que estuvo preso en la casa-tina de don Diego Farfán de los Godos y en la Real Cárcel de SM de Piura. Y, que ahora está preso por haber dado muerte al "cholo de Sechura" y esto ocurrió durante un forcejeo sin darse cuenta el cholo que él tenía un cuchillo debajo del poncho que usaba. Finalmente, relata que por el miedo que le provocaron los indios de Sechura, se fugó hacia los médanos de este pueblo y que cuando empezaron a quemar los árboles de chilco en la que se ocultaba, decidió entregarse a sus captores. Debe advertirse que esta declaración amplia de ME Baquíjano no fue firmada en esa ocasión (f.11).

En 17.07.1812, el subdelegado Monasterio designó para el cargo de fiscal a don Juan de Luque. Este comisionado eleva un escrito que resume la información de los hechos y considera que ME Baquíjano ha come-

6 Véase los ensayos de Alejandro Reyes 1999 y María Morales 2008. 
tido un delito grave al asesinar a un "hombre indefenso", José Rumiche, indio tallán (f.12), y que de acuerdo con la justicia y la religión, así como lo que manda el "Código Criminal" pide que se aplique la pena de muerte, "y que su ejecución sea sacarlo arrastrado a la cola de un caballo hasta el lugar del suplicio, para que refrene la perversidad de otros de su clase y que quede desagraviada la vindicta pública" (f.13).

Con estos testimonios, el subdelegado Monasterio informa en 01.08.1812, que el reo acusado disponía de nueve días para realizar su descargo y defensa. Y, que como goza de la categoría de forastero se le nombró un Defensor que en este caso es don Felipe Santiago Váldez, un vecino de oficio archivero (f.13). En efecto, ME Baquíjano informa que acepta la designación en 03.08. Así, este Defensor en su escrito señala que "entre las personas de su clase, es el Manuel Encarnación de aquella más ignorantes, demasiadamente rústicos, y que por estas calidades son dignos de ser tratados con alguna conmiseración”. En consecuencia, solicita que se le aminore la pena solicitada por el Fiscal, pues se trata de un hombre que vivía del miedo, y que como es de la categoría de prófugo, en este último acontecimiento el no tuvo la voluntad de quitarle la vida al indígena sino la de herirlo pues Rumiche quiso sujetarlo, y que lo que ocurrió fue el resultado de luchar por su libertad y proseguir con su fuga por el desierto (f.14).

A continuación y en 10.09.1812, el Subdelegado se traslada al pueblo de Sechura y allí ordena al alcalde Florencio Chunga que realice el recojo de los testimonios orales y la ratificación de los testigos siguientes:

\begin{tabular}{lc}
\hline Nombres y apellidos & Edad \\
\hline Narciso Rumiche & 48 \\
\hline Vicente Eche & 45 \\
\hline Antonio Eche & 28 \\
\hline Martin Eche & 37 \\
\hline Juan Vite & 51 \\
\hline Isidoro Tumi & 51 \\
\hline José Panta & 26 \\
\hline
\end{tabular}

En esta ocasión, todos declararon ser indígenas del pueblo de Sechura y que no sabían firmar (f.16-19). Estos testimonios orales se recogieron con la presencia del alcalde de Sechura, del Juez Real Subdelegado por SM, Comandante Militar, Capitán Agregado al Estado Mayor de la Plaza de Lima y del Protector Substituto de naturales don Miguel María de Adrianzen (f.16).
Días después, en 17.09, el subdelegado ordenó que los autos judiciales sean trasladados al Estudio del Doctor don Joaquín Suarez, abogado de la Real Audiencia de Lima, para que pudiera alcanzar su opinión (f.19). Para esta fecha ME Baquíjano toma conocimiento de los autos realizados, y de igual forma su Defensor Felipe Valdés y el Fiscal designado.

El informe entregado por el Subdelegado en 09.11, resume lo avanzado en este proceso judicial: que el Promotor Fiscal ha probado lo que manda el Derecho; y que condena a ME Baquíjano, reo convicto y confeso, de haber cometido un homicidio alevoso, y que se pide que se le aplique la pena ordinaria de garrote, y que este castigo deberá ejecutarse en la plaza pública de Piura para que sirva de ejemplo y de escarmiento de otros (f.21). Añade, que en este caso el reo deberá ser arrastrado de la cola de un caballo, desde la Real Cárcel hasta la plaza central de la ciudad de SM de Piura. Se anota, que esta sentencia, antes de realizarse, deberá ser comunicada a la Real Sala del Crimen para su aprobación real. Y para este efecto, firma este informe y lo acompańa con el dictamen del Asesor y la anuencia del escribano público de Cabildo, Minas, Registros y Real Hacienda de SM de Piura y SM, don Antonio del Solar (f.21).

Ese mismo día, en 09.11, don Felipe Valdez le informa de la sentencia y el trámite a seguir a ME Baquíjano, siendo testigo Pedro Ruiz, cabo veterano y alcalde de la Real Cárcel de Piura. Para su suerte, se anota que el Fiscal don Juan de Luque se encuentra ausente pues había viajado a la ciudad de Lima.

Mientras tanto, el Subdelegado informa en 23.11 que los autos criminales de ME Baquíjano habían sido remitidos al Superior Tribunal de Justicia de la ciudad de Lima para que esta resuelva lo que estime de justicia. A un costado de este escrito se anota y se registra que se ha recibido el expediente en la ciudad de Lima en 10.12.1812.

En la ciudad de Lima se vive otro clima político por la jura de la Constitución de Cádiz en octubre de 1812. En esta ocasión, la tensión social es creciente entre los sectores absolutistas y los constitucionalistas. De tal forma que en la ciudad de Lima, el 14.12.1812, el Fiscal del Crimen, don Miguel de Eyzaguirre informó que "hallándose insólenme la sentencia y notificaciones ultimas, por cuyo motivo acaso o por la prisión del infiernillo, en que se halla el reo, o por descuido o impericia no se había interpuesto recurso de apelación, podría V.A, si fuera servido mandar, se devuelva para 


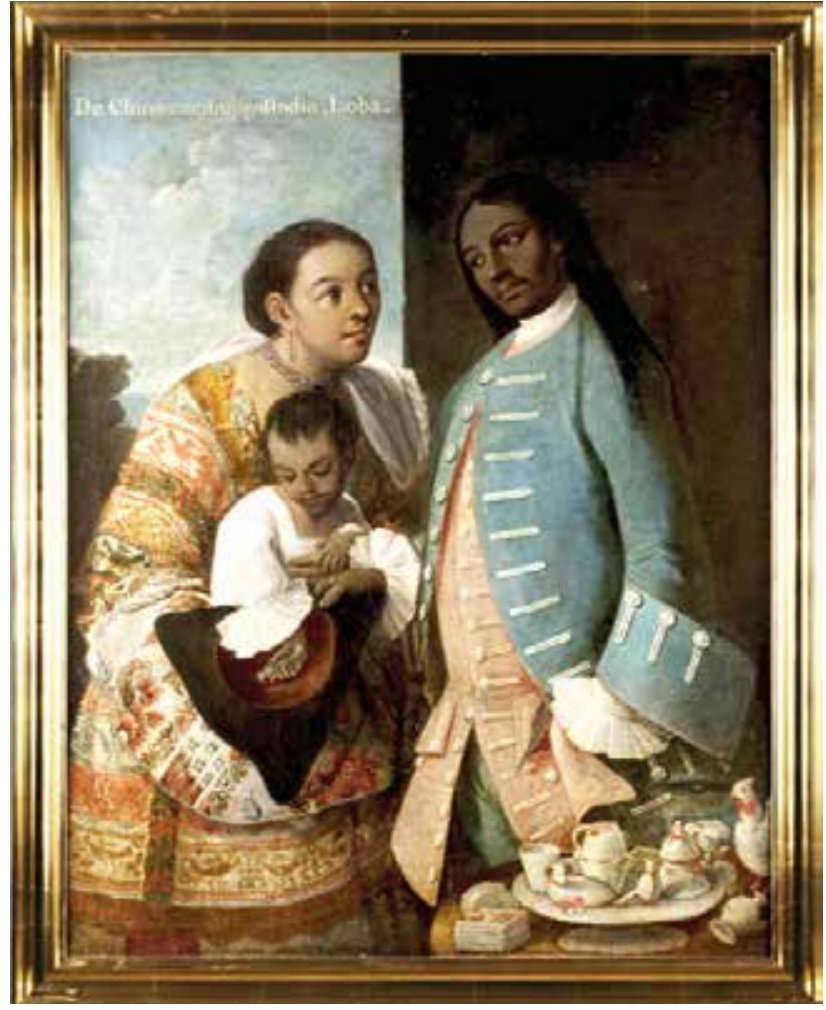

Figura 1. Zambos en América, siglo XVIII. Miguel de Cabrera. 1763. De Chino cambujo e India, Loba. MAM 00011. Museo de América (Joaquín de Otero).

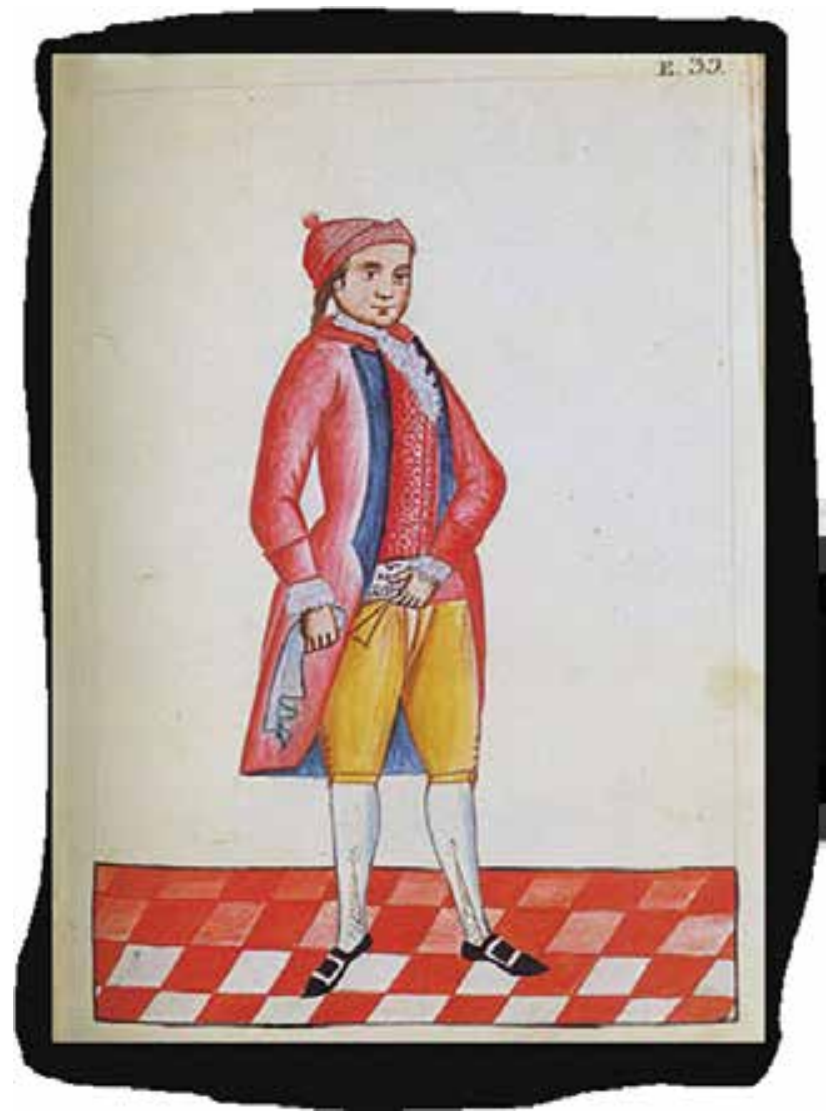

Figura 3. Acuarela de un cuarterón. Martínez de Compañón.

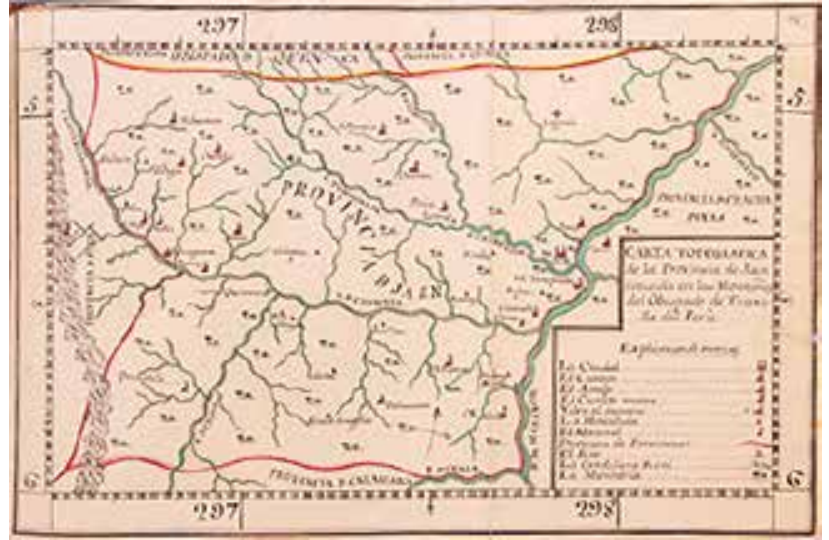

Figura 2. Mapa de Piura. Martínez de Compañón, 1784.

que autorizando la sentencia, o firma de juez que la pronuncia, el Escribano, o por su ausencia dos testigos, como también las notificaciones, y dejando correr el término de la apelación, consulte oportunamente y sin perjuicio se extraiga al reo del infiernillo y lo mantenga con la buena custodia prevenida en el artículo 297 de nuestra Constitución Política o lo que mejor parezca" (fs. 22v-23).

En consecuencia, en 17.12.1812, desde la Sala Real del Crimen, se ordena que por Autos y vistos, con lo expuesto por el señor Fiscal "mandaron se devuelva este proceso al Subdelegado de Piura para que subsane los defectos que advierte su Ministerio y observe lo pedido en la Vista que antecede" (f.23). Este escrito lo confirmará el señor doctor don Miguel de Eyzaguirre, del Consejo de Su Majestad y Fiscal del Crimen de la Real Audiencia de Lima (f.23). En efecto, en 05.01.1813, el subdelegado de Piura avisa que ha recibido el expediente y que ha tomado nota de los defectos o reparos señalados y propuestos, y ordena que se hagan las nuevas notificaciones. Esta vez manda que el reo salga del infiernillo (calabozo). Añade que en esta ocasión no está presente el escribano y que firman lo realizado en calidad de testigos, don Francisco Portalanza y don Tomás Valdez. Se advierte que el Fiscal que examinó este asunto está también ausente en la ciudad de Lima y que se cumplió con avisar de lo ocurrido al reo $\mathrm{ME}$ Baquíjano.

De esta forma, el expediente retorna a la ciudad de Piura. El giro judicial del expediente de ME Baquíjano es un acontecimiento político singular que es necesario analizar pues otras gentes de la ciudad de Lima como el

$7 \quad$ Sobre la coyuntura política-festiva en la ciudad de Lima en 1812 se puede consultar a Pablo Ortemberg (2012 y 2014) y Alberto Flores Galindo 1984: 139-184. 
Conde de la Vega del Ren y don José de la Riva Agüero también habían sido desterrados hacia otros puntos del virreinato del Perú por el virrey Abascal. ${ }^{8}$

Lo que ha ocurrido en la segunda mitad del año de 1812 y comienzos de 1813 es que el tiempo histórico y político había transitado de las reformas borbónicas a la crisis de la monarquía espańola y que se vivía un ambiente de formación de juntas de gobierno en varias ciudades de Hispanoamérica. Son años en que se asiste en la América hispánica y en Piura a un proceso de refuerzo y de consolidación política del cabildo o Ayuntamiento Constitucional, y un proceso singular de la elección de diputados a Cádiz. Lima es una ciudad de negros libertos y de negros esclavos. ${ }^{9}$ Se vive una situación histórica y política muy específica aunque no única, la victoria gradual de los cuerpos intermedios del antiguo régimen sobre el representante virreinal. Este caso judicial otorga una variedad de indicadores sobre el peso que está alcanzando el municipio para el gobierno y la construcción de una nueva autoridad a nivel regional al norte del virreinato del Perú. ${ }^{10}$

Para conocer la situación política en la provincia de Piura encontramos un escrito de don Felipe Valdés, Defensor del negro ME Baquíjano, quien informa que en 17.12.1812, se promulgó la Constitución Política de la Monarquía Española y también el Real Indulto de Delitos en la ciudad de SM de Piura. Añade que el caso que examina se encuentra incurso a esta soberana disposición y que así lo debe cumplir el Subdelegado y dar cuenta a la Real Sala del Crimen de Lima para que se realice la conmutación de la pena de muerte descargado sobre el negro ME Baquíjano (f.24).

Por otro lado, se conoce que el subdelegado de Piura informó en 07.01.1813 que en la plaza pública de esta ciudad se publicó la Constitución Política de la Monarquía Española, y también el Indulto, ambos decretos sancionados por las Cortes Generales y Extraordinarias de Cádiz. En consecuencia, ordena que se remita los autos criminales a la Real Sala del Crimen de Lima. Pero advierte que para esta fecha no está presente el escribano real. En la cárcel ME Baquíjano recibió esta grata noticia y de igual forma su Defensor don

8 Sobre Riva Agüero y el Conde de la Vega del Ren puede revisarse César Pacheco Veliz 1954: 355-425 y Scarlett O’Phelan 2012 y 2014: 193-237.

9 Maribel Arrelucea 2009 y Carlos Aguirre 1993.

10 Sobre Cabildos Constitucionales he consultado a Claudia Guarisco 2004; Víctor Peralta Ruiz 2012: 311-348; Marissa Bazán Díaz 2013; José Carlos Chiaramonte 1999: 94-116 y Gabriella Chiaramonti 2005. Para el caso específico de Piura puede consultarse a Julissa Gutierrez 2013: 157-180.
Felipe Valdés. Esta vez firman en calidad de testigos don Tomas Valdés, José Amunátegui y Manuel Iginio Matiz (f.24v).

La vida política en Piura también está complicada con las elecciones. Entre el 08.01 y 21.01 se demora el traslado de los autos judiciales de la ciudad de Piura a la de Lima (f.25). En 25.01.1813, el Fiscal Miguel de Eyzaguirre informa que recibió la petición de Indulto solicitado por el Subdelegado y anota que esta no procede (pues se trata de un homicidio alevoso), ya que este delito está exceptuado de la gracia y recomienda al subdelegado "podrá V.A declararlo no comprendido") y nombrar un abogado y procurador para la defensa del delincuente, y ordena que se le entregue estos autos para que interponga los recursos convenientes a su voluntad (f.25v).

A continuación, en 05.02.1813, en la Real Sala del Crimen se le nombra un abogado en la persona del licenciado José Mantilla, y de Procurador a don Manuel Molina; y se ordena que a ambos se le entregan los procesos y autos judiciales (f.26) para su examen. De esta forma, el primero que remite un escrito es don Manuel Molina, Procurador de Número de la Real Audiencia, quien informa que actúa a nombre de ME Baquíjano, y precisa que este caso no se encuentra comprendido en la gracia del indulto publicado, y por tanto, suplica se sirva reformarlo y la admita. Solicita nuevamente que se le entreguen los autos judiciales (f.27). En 13.02.1813, lo recibe el Fiscal y después don Miguel de Eyzaguirre, quien en 17.02, informa que ha visto la súplica de la negación del indulto y admite el recurso presentado.

De nuevo, don Manuel Molina presenta otra solicitud escrita y esta vez don Miguel de Eyzaguirre, Fiscal de la Real Audiencia Constitucional de Lima, informa en 23.02, que ME Baquíjano actuó con violencia contra Rumiche quien no manejaba ninguna arma y que solo estuvo buscando una bestia. De allí concluye que este caso está excluido del Indulto, y que no se insista, pues ya se le había negado una vez. Añade finalmente que "el tribunal hará la justicia" (f.29v) y así se lo comunica mediante otro escrito al Procurador don Manuel Molina en 09.08.1813.

En buena cuenta, habiendo ya transcurrido cerca de medio año, y ante un nuevo escrito de Manuel Molina, Eyzaguirre le comunica en 23.08.1813, que se ha confirmado la sentencia de la primera instancia por haber cometido la muerte alevosa y dolosa contra un indígena del pueblo de Sechura (f.34). 


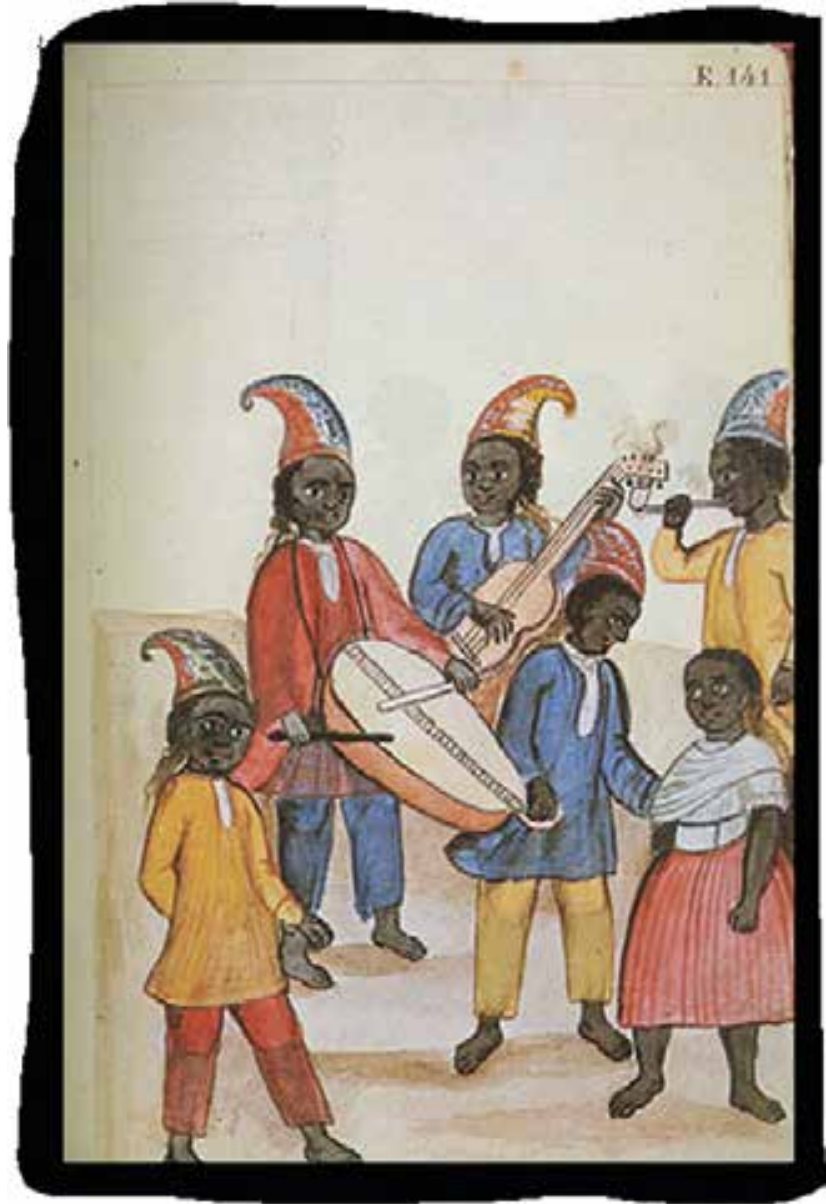

Esta vez, en 06.10.1813, la Real Sala del Crimen comunica mediante un escrito que se ha confirmado la sentencia dictada por el Subdelegado de Piura contra ME Baquíjano, y se ordena el envío de los autos judiciales para su ejecución y cumplimiento (f.34v) a la ciudad de Piura.

Ahora bien, en medio de este trajín de los papeles que viajan miles de kilómetros entre Piura y Lima. Ocurre otro suceso singular pero recurrente en la historia política de Piura. El Subdelegado de Piura avisa en 9.11.1813, que ha recibido los autos judiciales pero que no puede realizar la sentencia y ejecución de la muerte por garrote pues Manuel Encarnación Baquíjano y otros reos habían fugado de la Real Cárcel en 8 de julio de ese ańo (f.35).

\section{RELACIÓN DE PRESOS QUE SE HAN FUGADO DE LA REAL} CÁRCEL DE SM DE PIURA, 1813.

\begin{tabular}{ll}
\hline Nombres y apellidos & Casta o apelativos \\
\hline Manuel Encarnación Baquíjano & Negro esclavo de Cañete \\
\hline Juan José Sarco & Zambo, alias Chincho \\
\hline Rufino y Juan de la Cruz Adanaqué & Sin datos \\
\hline Guaman y hermanos & Indios de la hacienda Guapalas \\
\hline Bonifacio Atocha & (a) El panzón de la cordero \\
\hline Pedro Aguirre & Zambo (a) Pedro Malo, esclavo \\
\hline Ignacio Carrasco & Sin dato \\
\hline Bernardino & (a) El chileno
\end{tabular}

Figura 4. Músicos negros. Martínez Compañón.

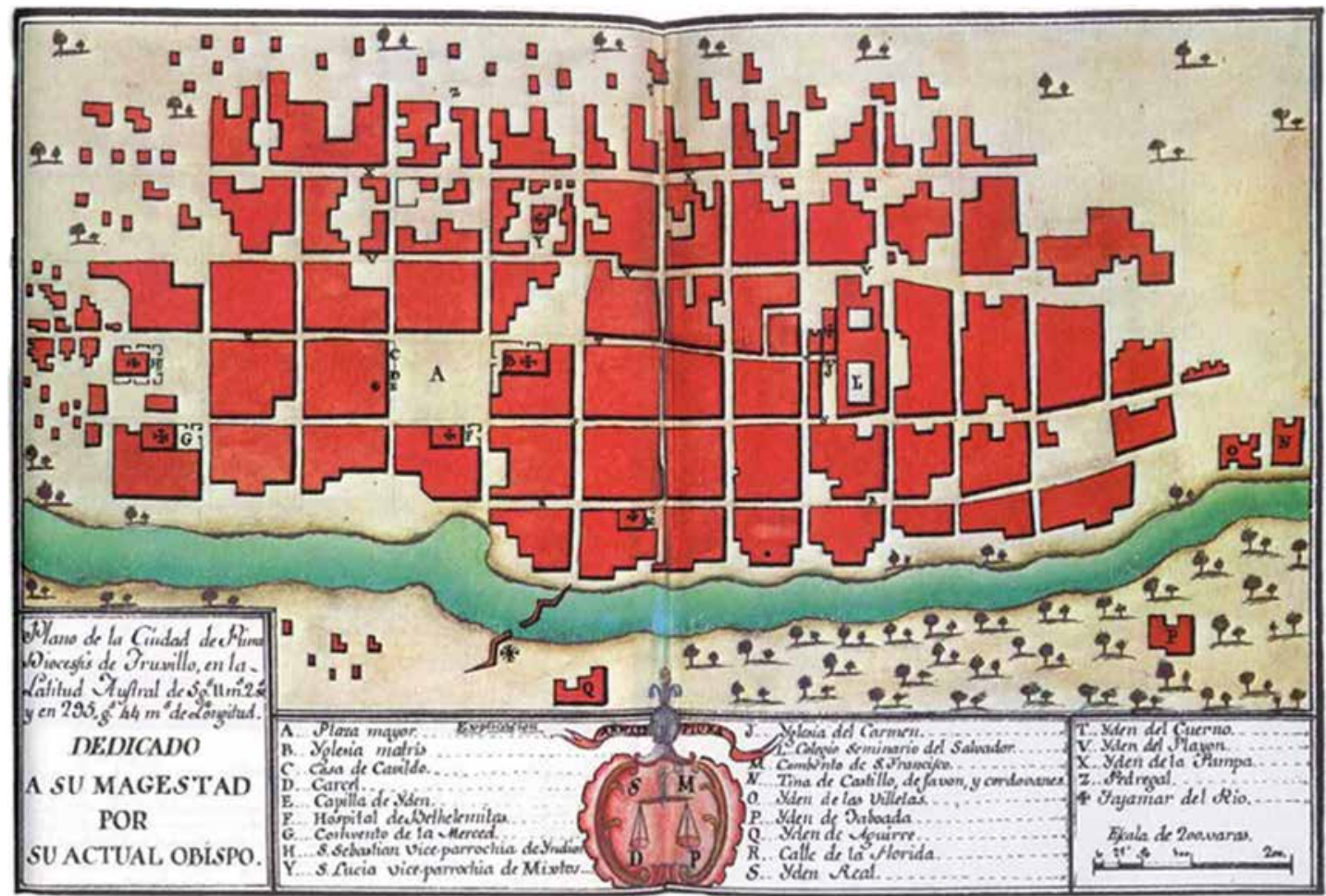

Figura 5. Plano de la ciudad de Piura. Martínez Compañón. 
En efecto, la fuga masiva de la Real Cárcel se realizó en julio y recién en 01.09, se remite un informe a la Real Sala del Crimen de Lima. En 22.11.1813, el Subdelegado envía un aviso a los Partidos confinantes para que colaboren en la captura de los prófugos (f.35v). El expediente se corta con este escrito y no se conoce cuáles fueron los resultados alcanzados a finales del año de 1813.

Ahora bien, en otro expediente consultado se encuentra información adicional sobre este acontecimiento social que parece haberse agudizado con la proclama pública de la Constitución de Cádiz (1812) pues a la ciudad de Piura llegaba un nuevo Subdelegado, don Bernardo Fernández. ${ }^{11}$

En efecto, este funcionario real escribe en 09.07.1813, informando que el carcelero Esteban Azaña había encontrado al amanecer de ese día tres forados por donde se habían fugado los reos y presos, y que para conocer los detalles de este hecho, ordena que Azaña junto al Escribano y el herrero Nicolás Escobar realicen un inventario de las chapas y cerraduras de los cepos y la puerta del infiernillo, para luego emitir otro escrito de requisitorias a los Partidos circundantes (f.1-1v).

El Subdelegado se encuentra conmocionado por este suceso que ocurrió apenas tomó posesión de su cargo político en Piura. Así, junto al escribano don Antonio del Solar y el maestro-herrero, Nicolás Escobar describen la situación en la que se encuentra el local de la cárcel: que esta se encuentra en un sitio que cae junto a una casa en la que "habitan unas mujeres pobres" (f.1v), y verifican los tres forados levantados por los reos y también que la chapa del infiernillo y la chapa-cerradura fueron abiertos con una llave maestra. No se tiene noticias de la hora exacta en que se produjo la fuga.

A continuación, el Subdelegado Fernández informa de la fuga masiva con mucho detalle al Intendente de Trujillo, don Vicente Gil de Taboada en 31.07.1813. Precisa que la fuga de los reos se produjo en la noche del 09 de julio y que después de esa fecha se dictaron las órdenes de captura. De tal forma, que en 18.08, el Alguacil Mayor de Trujillo, don Francisco Rodríguez manifiesta mediante un escrito que no han sido ubicados los reos fugados. De otro lado, desde la ciudad de Loja, en 12.08.1813, don Tomás Ruiz Gómez de Quevedo, también informa que hasta esa fecha no se había podido ubicar a los fugitivos.

11 ARP, 1813, Intendencia, Causas Criminales, Legajo 68, Expediente 1374.
RELACIÓN DE REOS Y TIPO DE DELITOS DE LOS QUE FUGARON DE LA REAL CÁRCEL DE PIURA

\begin{tabular}{|c|c|c|}
\hline Nombres y Apellidos & Tipo de casta & Delitos \\
\hline $\begin{array}{l}\text { Manuel Encarnación } \\
\text { Baquíjano }\end{array}$ & $\begin{array}{l}\text { Esclavo, negro } \\
\text { criollo }\end{array}$ & Homicidio \\
\hline $\begin{array}{l}\text { Juan José Sarco (a) } \\
\text { Chincho }\end{array}$ & zambo & $\begin{array}{l}\text { Robo de un zurrón } \\
\text { de plata }\end{array}$ \\
\hline $\begin{array}{l}\text { Rufino y Juan de } \\
\text { la Cruz Adanaqué; } \\
\text { Guamán hermanos }\end{array}$ & $\begin{array}{l}\text { Indios de la } \\
\text { hacienda Guápalas }\end{array}$ & $\begin{array}{l}\text { Muerte de indio } \\
\text { Mateo Villegas }\end{array}$ \\
\hline $\begin{array}{l}\text { Bonifacio Atocha (a) } \\
\text { Panzón de la Cordero }\end{array}$ & & Vida desordenada \\
\hline $\begin{array}{l}\text { Pedro Aguirre (a) Pedro } \\
\text { Malo }\end{array}$ & Esclavo; zambo & $\begin{array}{l}\text { Huyó del poder de } \\
\text { su amo }\end{array}$ \\
\hline Ignacio Carrasco & & $\begin{array}{l}\text { Robo de unas cabras } \\
\text { en Salitral }\end{array}$ \\
\hline $\begin{array}{l}\text { Bernardino (a) el } \\
\text { chileno }\end{array}$ & & $\begin{array}{l}\text { Robo de piezas de } \\
\text { sarasa. }\end{array}$ \\
\hline
\end{tabular}

Días después, en 26.07, don Francisco Méndez Pabón comunica al Subdelegado que los peones indios de su hacienda de Curvan habían logrado capturar al zambo Juan José Sarco, (a) Chincho, y que lo estaban conduciendo a la ciudad de Piura (f.8). En 26.07, este zambo ingresó a la cárcel bajo el cuidado del alcalde Esteban de Azaña (f.9). Finalmente, el 26.07, el Subdelegado informa que los autos judiciales de los reos Juan José Sarco (a) Chincho, Juan Crisóstomo Saavedra, Roque Echeverre y José Goméz fueron enviados en el correo del mes de junio a la Real Sala del Crimen de Lima (f.9) para su dictamen real.

\section{Los criollos en Piura y la Constitución de Cádiz. La pugna entre dos fuerzas, la exclusión formal y los esfuerzos integradores de la población afrodescendiente.}

En la historiografía regional de Piura falta estudiar cómo la Constitución de Cádiz cambió fundamentalmente las condiciones generales de la población afrodescendiente para negociar su posición dentro de la sociedad.

La Constitución de Cádiz liquidó gradualmente el sistema virreinal de las Repúblicas de "Indios y de Españoles". Se anuló la separación administrativa y se proclamó que todos los habitantes libres son ahora "españoles". Sin embargo, la carta gaditana restringió los derechos civiles plenos, entre ellos el derecho a la participación política formal, esta vez activada sólo a los que gozaban la categoría de "ciudadanos". Es 
decir, no existía la ciudadanía completa sino limitada, mutilada.

Esta vez, desde el Estado virreinal y el gobierno regional se impone y se difunde la categoría de "ciudadanos" con sus derechos civiles y espacios de participación solo para una parte de la población de la monarquía hispana. En esta coyuntura política los afrodescendientes estaban excluidos.

De tal forma que los incluidos a la categoría de ciudadanos son los españoles e indígenas varones; así, solo una parte goza del derecho de la participación electoral y de elegir a sus representantes. La ley estableció también una nueva frontera a los sacerdotes y presbíteros, a los empleados domésticos, a los criminales y a las autoridades públicas que adeudaban a la Real Hacienda.

En los debates sobre los afrodescendientes se plantearon varias posiciones, unos apoyaban la inclusión y otros la exclusión. Se llegó a afirmar que: los negros no son naturales de los dominios españoles sino extranjeros. Mientras que otros diputados planteaban que los negros son españoles con sentido de patria y que luchaban bajo la forma de milicias y de militares contra los insurgentes. Por tanto, exclamaban que todos los hombres son iguales y que debían de gozar de los derechos de la igualdad universal. Por tanto, exigían la abolición del sistema de las castas y la igualdad de todos los grupos étnicos. ${ }^{12}$

La votación final aprobó la exclusión agregando en el artículo 22 de la Constitución la posibilidad de la ciudadanía bajo el sistema de la meritocracia, es decir, alcanzarlo a cambio de realizar ejemplares servicios a la patria espańola. O sea, que no goza de la igualdad política proclamada por la Cortes de Cádiz de 1812.

En Piura se dio lectura y se juramentó colectivamente la Constitución de Cádiz; en esta ocasión se realizó un acto festivo de celebración constitucional acompańado por la presencia de un nuevo Subdelegado real. Los vecinos asistieron a esta ceremonia organizados en barrios y parroquias. Los habitantes de la ciudad no estaban separados esta vez por castas ni tampoco entre "españoles" y "ciudadanos", sino por una distribución de barrios que se habían expandido paralelamente a la orilla del río Piura y entre pequeńas capillas y una Iglesia central ubicada en la plaza pública en la que ahora se encontraba el Ayuntamien-

12 Véase este debate gaditano en Scarlett O'Phelan 2014: 79-113. Para otros contextos de Hispanoamérica también puede examinarse a Carlos Sánchez Silva y Luis A. Arrioja. 2008: 82-125; Zamira Díaz López 2006: 59-75; to Constitucional, la Real Cárcel, el Convento y Hospital de Santa Ana y los solares de las familias más ricas de la provincia y vecinos forasteros. (Espinoza Claudio 2016: 117-138).

Las tropas se reúnen en la plaza central y se da lectura de la Constitución de Cádiz. Luego viene el juramento de los oficiales y las tropas que portan las banderas y sus armas de fuego. Esta vez asisten todas las tropas de la ciudad, los batallones de blancos y las de pardos. No sabemos todavía si las tropas de Payta realizaron el juramento de la Constitución de 1812 en ese puerto o se trasladaron a San Miguel de Piura. Este acto de reconocimiento simbólico del nuevo orden en España en la que gobernaba una Junta y no Fernando VII se empieza ya a difundir la idea de la formación de una nueva comunidad nacional, la nación de España.

En esta ocasión se busca que la idea de la unidad de la "nación" aglutinara a los habitantes de Piura, pero también empieza a funcionar otro elemento de diferenciación entre las gentes "españolas" y la de los "ciudadanos". Este último es un indicador y un mecanismo de exclusión política pues no todos gozan de este derecho y categoría social en Piura.

Las elecciones para elegir a los alcaldes y regidores en SM de Piura se realizan sin mayores obstáculos. De igual forma ocurrió en el proceso de designación de los diputados a las Cortes en 1812. Las elecciones que se realizan en el pueblo de La Punta (6 de enero de 1814), un centro poblado organizado al interior de la hacienda de la Capilla, son bloqueadas políticamente por las autoridades elegidas en SM de Piura.

En efecto, los alcaldes de SM de Piura presentan una variedad de recursos legales para anular esta elección orientada a organizar un nuevo poder local institucionalizado bajo la forma de un Cabildo Constitucional en el valle de La Chira. Para bloquearlo se informa que se trata de una acción ilegal de mucha gente rústica y que entre los miembros elegidos se encontraban individuos de sangre africana, mulatos y zambos, es decir, gente originaria del Africa que prohibía la Constitución de Cádiz.

Con este argumento y otras argucias legales, las autoridades de SM de Piura insistieron en la supresión del derecho de voto para las gentes consideradas "extranjeras", es decir, ser originarios de Africa. Se concluye que los afrodescendientes varones son "españoles africanos" pero sin el goce del derecho de la ciudadanía y de participación en los procesos electorales. 
Los escritos enviados señalan que para esta población no existía una plena "igualdad civil y política", es decir, que los varones afrodescendientes no gozaban del derecho a la ciudadanía. Se les había impuesto estas delimitaciones jurídicas por su condición de "extranjeros" y ser originarios del Africa. La gente del lugar se encontraba desconcertada pues las milicias de pardos no gozaban de la ciudadanía pero si son considerados españoles, es decir, miembros de una nación en proceso de construcción en medio de una guerra contra la Francia napoleónica.

Los milicianos pardos no tienen el derecho de la ciudadanía. Sobre este asunto no conocemos todavía la posición del cura-vicario de Piura y si se iniciaron las gestiones para que se extienda la ciudadanía a los milicianos pardos. Es muy escasa la información sobre si postuló los principios igualitarios o el sistema de la meritocracia al interior de los batallones de pardos.

Las autoridades de SM de Piura apostaron por la exclusión de las autoridades elegidas en la Punta de Tillopaira y la liquidación política de la junta de gobierno designada, decisión que finalmente la tomó el virrey Abascal quien buscó mayor información y apoyo en la elite criolla de SM de Piura.

En efecto, los pardos no lograron alcanzar la categoría de ciudadanos, por el contrario, son marginados y excluidos de la vida política entre los ańos de 1812 y 1814. Tampoco se conocen la documentación sobre la falta de reconocimiento material y moral por los servicios que prestaron los milicianos pardos para combatir a los insurgentes por mar y tierra, dentro y fuera de la provincia de Piura. A finales de 1814 retornó al trono español Fernando VII y la Constitución de Cádiz es anulada y por consiguiente, la separación entre ciudadanos y no ciudadanos, retornó así la vieja idea de una sociedad señorial y jerarquizada (O'Phelan Godoy 2012a: 196-228).

\section{El marqués de Salinas y su furia colérica contra los milicianos pardos}

En efecto, en 1809, don Francisco Xavier Fernández de Paredes (FXFP), marques de Salinas, dueño del latifundio de Tangarará, ubicado en el valle de La Chira se queja del comportamiento practicado por los milicianos de la ciudad de SM de Piura. Así, en 26.01.1809, don FXFP elevó un escrito al Co- mandante Militar y Teniente del Ejército, don José López. ${ }^{13}$

De otro lado, en 01.02.1809 don ML Farfán de los Godos, informa al Comandante José López, acerca de los ultrajes y azotes realizados contra los milicianos de su cuerpo por el alcalde de la ciudad, don FX Fernández de Paredes. En esta ocasión, esta autoridad local mantiene preso en la cárcel de la ciudad a José Gregorio Cortes. Este miliciano es capturado y conducido a la cárcel por los "sitiopas" que se encuentran a su servicio, violando "las máximas de la política y urbanidad", inquietando al vecindario y rompiendo la paz, el sosiego y la buena armonía de la sociedad. En su escrito Cortes denuncia que se ha impuesto el capricho personal sin cuidar los "senderos de la prudencia y la discreción", además de "romper los diques del sufrimiento" provocado por los odios y resentimientos acumulados en estos tiempos.

El marqués de Salinas recuerda que ya en noviembre de 1808 existía un antecedente, pues también se le había practicado similar castigo a otro miliciano llamado José Antonio Rocha, quien por no acceder a salir de "Macero", ${ }^{14}$ de igual forma, se le dio muchos golpes en la propia casa de FXFP.

En los escritos que se encuentran en este expediente se precisa que en esa ocasión, don ML Farfán de los Godos estuvo de Ayudante Mayor de don Antonio Escobedo, permaneciendo en este puesto los tres años que duró la guerra contra los ingleses. Y, que en esta oportunidad las filiaciones los condujo el capitán don José González de la Cotera y don Miguel Vargas Machuca, entonces Ayudante Mayor interino. Fue este un tiempo en la que el Comandante General don Gavino Gainza, estuvo en la plaza de Piura acompańando a otros oficiales que permanecieron en la provincia.

Agrega que en este tiempo se solicitaron muchos varones voluntarios para servir a la patria y la guerra, $y$

13 ARP: 1809. Cabildo, Causas Criminales, Caja 19, expediente 371. Para reducir las reiteraciones de los nombres y apellidos citados, hemos sintetizado a Francisco Xavier Fernández de Paredes en FXFP y a Manuel Luis Farfán de los Godos por MLFG. De igual forma, ARP es Archivo Regional de Piura.

14 Macero. Se llama macero a un funcionario español que encabeza las comitivas municipales o de otras corporaciones luciendo un tabardo, uniforme de antiguo origen y llevando en su mano una maza. La presencia del macero en determinadas solemnidades y comitivas municipales es una tradición antigua que simboliza el poder de la autoridad. Antiguamente antecedían los desfiles de los reyes pero posteriormente se extendió a otras instituciones bien por delegación real, bien por representación propia, como los ayuntamientos. Luego, se extendió a otras corporaciones como figura representativa de su autoridad y han llegado a nuestros días en muchos pueblos y ciudades de España. https://es.wikipedia.org/wiki/ Macero. Consultado en 15.02.2016. 
fue el caso que esta vez se presentó JG Cortés, "como también en la guerra reciente cuando le acometió el ynglés a la Astrea, se pidió el auxilio a esta ciudad, el que conduje con otros oficiales, y entre ellos a Cortes, y si ha faltado a los ejercicios ha sido por estar en Lima, Panamá y en los campos de esta provincia buscando para su subsistencia, y cuando ha llegado a estar en la ciudad no ha podido presentarse en la plaza por su indecencia" (f.9).

Recuerda también que en el año de 1807, el alcalde de primer voto y el Subdelegado, le pidieron licencia para que como miliciano JG Cortés pudiera declarar como testigo en el Juzgado en una causa seguida contra Francisco Porras. A todo esto se suma el hecho de que también recibió la demanda que le hizo el arpero Diego Seminario, quien lo acusaba de haberle cortado las cuerdas del arpa en la calle o puerta de Manuela Maticorena, y que cuando lo iba a traer, JG Cortés le ofreció pagarle el costo. Un suceso particular que había sucedido a las siete de la mańana, y ya para las once de esta misma mańana, el alcalde FX Fernández de Paredes lo había apresado y puesto en la cárcel acusado por don Agustín Navarrete de haberle faltado el respeto a las Maticorenas (f.9).

Pero lo cierto es que en este caso se sabía que Navarrete le adeudaba una cantidad de pesos a FX Fernández de Paredes, y que a cambio de ayudarlo le hizo este favor para demandar a JG Cortés, y por tanto, pasó a meterlo a la cárcel y al cuartel sin realizarle la sumaria respectiva.

Anota que en este caso se ha cometido una grave injuria con el castigo de los azotes a los milicianos, y que para evitar esta tropelía no ha pasado a la cárcel. Para confirmarlo, pide que declare José Manuel Bustamino, mulato portugués, un sujeto afiliado a la nave Astrea.

Días después, en 27.01.1809, don ML Farfán de los Godos, regidor Fiel Ejecutor, Capitán y Comandante Accidental del Batallón de Infantería Disciplinada de San Miguel de Piura, declara que don FX Fernández de Paredes, en el tiempo de su mando como alcalde, había abusado de varios milicianos poniéndolos en la cárcel pública, violando de esta forma la jurisdicción militar. Y que para hacer justicia solicitó que se recogieran los testimonios orales sobre esta materia y que el resultado se remitiera a la Capitanía General del Reino (f.10).

En este caso, el primer testigo entrevistado se llama Bernardo Romero, edad 40 años, sabe firmar, Sargento de la Segunda Compañía del Batallón en Piura. Seña- la que hace más de un año, cuando FX Fernández de Paredes fue alcalde, ocurrió que cuando estuvo parado en la puerta de su casa su sobrino Sebastián Romero y Sierra, miliciano de Infantería, jugando con un hijo de don Pedro Otoya, lo hizo agarrar con sus criados, lo metió a su casa y "lo mandó azotar a uno de sus negros y que al presente puso preso en la Real Cárcel al miliciano José Gregorio Cortés" (f.10v). Añade, que escuchó en el vecindario que lo mismo le había ocurrido al miliciano José Antonio Rocha, por "haber querido salir de macero en la Jura del Rey Nuestro Señor Don Fernando VII (y que) lo estropeó dándole guantadas, estando de alcalde" (f.10v).

Un segundo testigo es don José Angela Marques, edad 30 años, sabe firmar. Teniente de Alguacil Mayor, miliciano de la Primera Compañía de Disciplinados de Lima. Este afirma que FX Fernández de Paredes llamó en una ocasión a un miliciano para luego azotarlo. También sabe que puso a otro miliciano llamado José Antonio Rocha en la Real Cárcel de Piura. Pero que a los pocos días este fugó de este local y se refugió en el cuartel. Y que enterado de este suceso FXFP realizó las gestiones para que retornase a la Real Cárcel y le encargó cumplir esta misión al declarante. De esta forma fue que Rocha pudo contarle todo y que se había complicado pues antes de llevarlo a la cárcel don Fernández de Paredes le había descargado muchos golpes, puñetes y patadas. De igual forma sabe también que siendo alcalde FXFP, este le ordenó capturar a JG Cortes y al mulato portugués José Manuel Buscamino (marinero afiliado a la fragata La Estrella en el puerto de El Callao), a quien también lo puso preso en su hacienda de Tangarará y descargándole más de 50 azotes en calidad de castigo (f.11v-12).

El testimonio de Sebastián Romero y Sierra confirmó los abusos cometidos por FX Fernández de Paredes, entonces alcalde de segundo voto de Piura, quien mandó capturar y poner preso al miliciano JG Cortés, y aprovechó también para descargarle muchas bofetadas al miliciano JA Rocha. Y dice, que todo esto llegó al extremo en la que FX Fernández de Paredes lo llevó a su casa con ayuda de sus criados y fue en este sitio que le descargó doce azotes, pese a señalarle que gozaba de la condición de miliciano (f.13).

A continuación se registra la declaración oral de don José Antonio Rocha, edad 26 años, miliciano de la Primera Compañía de Infantería de San Miguel de Piura, quien afirma que sabía firmar. Rocha relata que FX Fernández de Paredes lo llamó para que "saliese de 
Macero en la Jura que se iba a hacer de Su Majestad don Fernando VII, y que primero lo aceptó, pero que cuando le avisaron que saldría con un tal Moncayo, le avisó que no lo haría "porque no le igualaba" (f.13v), y que mejor saldría en su compañía de milicias”. Así, frente a esta posición es que FXFP le ordenó a uno de sus negros para que lo llevase a la cárcel, y que cuando marchaba en el camino Rocha optó por fugarse y regresar a su cuartel. Al poco tiempo escuchó las voces del Sargento Primero, Manuel Fleita quien ordenó que saliese y le alcanzó su casaca; después, lo mandó llamar el TC Manuel Carrasco, quien le preguntó si era miliciano, y le dijo que sí, fue entonces que Carrasco le dijo que no lo había visto en la Plaza, y ordenó al Cabo Veterano, Pedro Ruiz a que lo llevase ante el alcalde FXFP, y fue que allí llegó con la casaca que le dio el Sargento llamándole la atención FXFP por llevar esta casaca, y que eso lo tomó como un insulto y que luego le dio una patada (f.14).

A continuación declara Pedro José Larrea, quien afirma ser europeo pero no precisa su edad. Confiesa que él vivía en un cuarto inmediato al local de la cárcel y que vio como FXFP trasladó a la cárcel al miliciano JG Cortés ayudado por un negro. Fue en esa ocasión que Cortés no quiso entrar al local carcelario y logró fugarse temporalmente por las calles vecinos. Es allí que el interviene junto a otro zambo y que logran recapturarlo y ponerlo a la cárcel a empujones (f.14v). No olvida señalar que recuerda que vio a Cortés cumpliendo su servicio en el puerto de Payta cuando se produjo "el combate que hubo" cuatro años atrás (1805) (f.15) contra los ingleses.

Finalmente, en una Sumaria realizada contra el guarda don Francisco Porras, por los insultos que le descargó el regidor don Antonio Cortes, siendo alcalde ordinario, se verificó que entre los testigos declarantes se presentó don José Gregorio Cortes, miliciano (f.1). Este documento es una copia otorgada por el escribano don Antonio del Solar en SM de Piura en 01.02.1809.

En este escrito fechado en 03.02.1809, don FX Fernández de Paredes informa a don Luis Godos, Comandante Accidental del Batallón de Infantería, que el Comandante José López cumplió con avisarle que tenía arrestado en el cuartel a JG Cortés y que contradictoriamente ha visto que "hoy está paseando públicamente por las calles de esta ciudad". Por lo tanto, solicita que se le informe las razones de su libertad y soltura (f.19).
Ese mismo día Godos pidió que le alcanzaran la información sobre esta denuncia. Fue don Prudencio de Anzuátegui quien le manifiesta que recibió la información de que el sargento Pedro Ruiz lo había dejado salir un rato para "tomar un bocado" pues no tenía nada para comer en el cuartel y que luego Cortés había regresado nuevamente al calabozo (f.20).

Con estos añadidos e información escrita, José López remite desde Paita, en 07.02.1809, un informe directo al virrey Abascal. Esta vez le pasa una copia del Expediente de Competencia de Jurisdicción iniciado por el alcalde de la ciudad de SM de Piura, don Francisco Xavier Fernández de Paredes, quien le había iniciado a JG Cortés (miliciano del Batallón de Infantería) una causa criminal y luego depositado en la cárcel de Piura. Adjunta a este expediente los testimonios de cinco testigos que verifican que JG Cortés gozaba de la categoría de miliciano activo en el puerto de Paita y que así figuraba en una lista confecciona$\mathrm{da}$ en el ańo de 1802. Pide por tanto que el virrey Abascal reprenda al alcalde de Piura por los abusos cometidos y que guarde la urbanidad y que deje de insultar a los jefes militares (f.22). Este oficio escrito es recibido por el Auditor de Guerra, en la ciudad de Lima en 21.02.1809, concluyendo y cerrándose el expediente judicial. ${ }^{15}$

\section{Conclusiones preliminares}

El impacto de la conquista de España y la guerra interna en los Andes provocará una declinación radical de la población indígena, lo que obligará a las autoridades a refundar la ciudad de SM de Piura en 1588, a repoblar los valles y a introducir masivamente mano de obra negra africana y criolla durante el siglo XVII y XVIII para jurídicamente adscribirlas a la república de los españoles bajo la denominación de "castas". Es así, que en Piura se encuentran individuos que declaran su pertenencia a los mandingas, angolas, caravelies, etc., $y$ que con el tiempo asumirán otras formas de categorización social identificándose como negros criollos, bozales, zambos, mulatos, chinos, etc. Avanzado el siglo XVIII se diferenciaran incluso entre negros bozales $y$ libertos, etc. Es un tiempo de avance del mestizaje biológico y cultural que todavía ha sido poco estudiado. (Jorge Moscol, 1986). Lo cierto es que en la pirámide

15 Véase anexo documental 1 al final del ensayo. 
social se le atribuyó a esta población el rango social más bajo entre todos los grupos sociales existentes.

En esta sociedad, la posición de los afrodescendientes era ambivalente: tradicionalmente, el estigma social de ser considerados como descendientes de esclavos hizo que se les atribuyera la categoría de clases ínfimas de la sociedad (Ricardo Alexandre: 2009: 339-376).

Los afrodescendientes vivían cargados de este estigma social pero también sus cuerpos estaban simbólicamente marcados con algunas señales que le impusieron sus dueńos y propietarios. En el discurso religioso se difundió la idea de que los africanos son descendientes de Cam, o sea, herederos de la maldición que Noé había descargado sobre su hijo. En la actualidad vasta visitar la iglesia de San Sebastián en la ciudad de Piura y descubrir cerca de la nave derecha una estatua del arcángel de San Miguel pisando la cabeza de un negro con cachos y los ojos desorbitados y aterrorizados por una lanza o espada que amenaza descargar sin piedad este santo cristiano. En los barrios de arriba (iglesia Virgen del Carmen) y en los barrios de abajo (iglesia San Sebastián), extremos oriente y poniente de la ciudad, se asentaron durante un tiempo varios grupos de familias de afrodescendientes que empezaron a vivir al interior de la ciudad para ofrecer su trabajo en tareas domésticas, de seguridad personal, de arrieraje, aguateros, etc., sin poder impedir que en su interior emergieran grupos de individuos, hombres y mujeres, dedicados al negocio de la artesanía, el comercio, la venta de dulces, comidas, licores y la acumulación de pequeñas fortunas monetarias y de alhajas de oro, plata, y toda clase de joyas como las esmeraldas y toda clase de piedras caribeñas.

Esta vez, negros esclavos y libertos se habían concentrado en la periferia y micro espacios urbanos, rodeaban prácticamente a las dos primeras cuadras de viviendas y mansiones levantadas a orillas del río Piura. En la práctica, estaban formal, jurídica y socialmente asignados a la "república de los espańoles", construyendo además una sociedad estratificada y con posibilidades de ascenso social de individuos y grupos de familias ligadas a los dueńos de haciendas y traficantes del algodón, la cascarilla, los jabones y los cordobanes.

A finales del siglo XVIII, en Piura, esta sociedad de castas estaba empezando a transformarse hacia otra sociedad de clases. La población afrodescendiente conserva su origen étnico pero también acumula pequeñas fortunas monetarias, propiedades de tierras, realiza negocios a nivel regional y gradualmente cambia de status de esclavo a liberto, a vecino, y a ciudadano. Los límites y el peso de lo económico y social empezaron a desplazar el origen étnico en el sistema de clasificación social de estos individuos que se les había impuesto durante el régimen de los Habsburgos.

La Constitución de Cádiz va a transformar los fundamentos que sancionaban los límites culturales vigentes. Avanza en Espańa y algunas ciudades de Hispanoamérica la idea de una nación inclusiva orientada a organizar una sociedad igualitaria e individual. En Huancabamba se difundió la voz en 1812 de que "Napoleón se encontraba en los Andes" pues las leyes gaditanas habían provocado un desorden y un gradual reordenamiento de los grupos de poder, enfrentándose, por ejemplo, los líderes provenientes de la sierra con otros líderes tradicionales de la costa, o también la movilización social de pueblos como Guarmaca, en la que sus líderes exigían que la cobranza y el tamaño del pago del diezmo no se modificara y que por el contrario se mantuviera la costumbre del "veinteno".

En España se impulsa el proyecto de la nación de la identidad española. Esta vez toda la población será categorizada como "españoles" y solo un sector será denominado "ciudadanos" portador de sus derechos civiles. En efecto, si los indígenas y los mestizos están incluidos en la categoría de ciudadanos, por el contrario, la población afrodescendiente quedará excluida. Los afrodescendientes no pueden alcanzar la categoría de ciudadanos y viven la exclusión política. El siglo XIX también es un siglo de intensificación del bandolerismo y el bandidaje rural en la provincia de Piura y en toda la costa norte del Perú (Milagros Carazas 2004 y Raúl-Estuardo Cornejo 1972: 309-337).

Sin embargo, la población afrodescendiente no se mantuvo quieto, por el contrario redoblaron sus exigencias de participación política bajo modalidades no convencionales como el cimarronaje y la migración hacia las cordilleras de Huancabamba y Guarmaca. Individuos y familias se asociaran a los grupos de criollos que están resistiendo a la dominación española. Este accionar aislado y disperso se intensificará cuando se verificó que la carta gaditana había excluido a la población afrodescendiente.

La historiografía del Virreinato de Nueva España ha estudiado la participación de la población afrodescendiente en el movimiento insurgente, y también sus luchas judiciales para suprimir las tradicionales categorías de la sociedad de castas. ${ }^{16}$

16 La bibliografía sobre afrodescendientes en México es vasta. Yo he 
Otro grupo de investigadores se han introducido al estudio de la participación política de los afrodescendientes en el contexto de las prácticas políticas orientadas por la Constitución de Cádiz desde 1812. Para el caso de la provincia de Piura se registra el hecho de como un pequeño grupo fue excluido, a escala local, en la organización y funcionamiento de los Ayuntamientos Constitucionales, como fue el caso de la Punta de Tillopaira (hoy Sullana) entre 1813 y 1814, y en la que concluyeron liderazgos afrodescendientes e indígenas y mestizos, de oficio labradores y criadores de ganado mayor y menor.

Miguel Arturo Seminario (1994) y Elizabeth Hernández (2008) trabajan este acontecimiento político pero de manera incompleta y presentan a los líderes y a la población que los acompańaba como una especie de "rebeldes primitivos" quienes son reprimidos por los terratenientes asentados en la ciudad de SM de Piura y apoyados por los religiosos y las autoridades de la ciudad de Trujillo y de Lima. ${ }^{17}$

En ambos trabajos no se presentan mayores detalles acerca de la organización de este grupo rural y los procedimientos que se usaron para establecer el funcionamiento de las nuevas categorías gaditanas en un espacio rural campesino y con un centro poblado rural en proceso de constitución (La Punta).

En el proceso judicial que revisamos se registra un alto número de testigos pertenecientes a diferentes castas. Casi nada se sabe de la participación de las milicias de color. En buena cuenta, labradores y milicianos fueron afectados de manera singular por la exclusión política que estaba sancionada por las normas de la Constitución de Cádiz.

En efecto, desde 1805 se militariza la región de Piura, la guerra entre España y Gran Bretaña registra su impacto en este espacio norteńo hacia la cual se dirigen las naves británicas procedentes de USA y la China. Las milicias de pardos servirán para imponer la seguridad de la frontera con la Audiencia de Quito y el puerto de Guayaquil. Las autoridades coloniales utilizan esta fuerza militar compuesta por afrodescendientes para enfrentar a los insurgentes de Guayaquil, Quito, Loja, Cuenca, Piura y Jaén de Bracamoros.

Faltan estudios para reconstruir el proceso de la reacción de los milicianos pardos y de la población

consultado a Juan José Benavides 2014; María de Lourdes Ghidoli 2013; Herbert Klein y Ben Vinson III 2008; María E. Velásquez y Gabriela Iturralde Nieto 2012, y Eric Van Young 2006.

17 Sobre la identidad, la historia y el mundo social de los negros esclavos de Yapatera (Piura) puede consultarse a don Fernando Barranzuela (2012) afrodescendiente ante la Constitución de Cádiz, y también la de conocer cómo se negoció la diferenciación socio-política entre los "ciudadanos" y "españoles" en la provincia de Piura. Reconstruir el contexto de la implementación de las nuevas categorías implica analizar la situación general y el posicionamiento de las milicias de pardos en la sociedad piurana a finales del siglo XVIII.

Estudiar las prácticas socio-políticas de los afrodescendientes y las adaptaciones locales generadas por la introducción de la Constitución de Cádiz en Piura en dos coyunturas $1812-1814$ y $1820-1824$, es un tema pendiente. El ensayo que ahora presentamos es un examen preliminar que apuesta por recuperar la voz de la gente de color y su accionar político y judicial, dimensiones de la vida social que ha sido silenciado y ocultado durante muchos siglos.

\section{Referencias bibliográficas}

Alexandre Ferreira, Ricardo (2009). Livres, escravos e a construção de um conceito moderno de criminalidade no Brasil Imperial. En: Historia (Sao Paulo), Vol. 28, N 2, pp. 339-376, Brasil.

Aljovín, Cristóbal (2016). Ocho verdades sobre las elecciones decimonónicas en el Perú. En: Participación, competencia y representación política; pp. 69-80. Contribuciones para el Debate. Escuela Electoral de la Gobernabilidad, JNE, IEP, Lima, Perú.

Aljovín, Cristóbal y Francisco NúŃEz (2006). Ensayo bibliográfico: las elecciones peruanas decimonónicas. En: Revista Elecciones; № 6; pp. 219-242. Lima, Perú. http://www.onpe.gob.pe/modEscaparate/ downloads/L-0034.pdf. Consultado en 08.07.2016.

Aguirre, Carlos (1993). Agentes de su propia libertad. Los esclavos de Lima y la desintegración de la esclavitud, 18211854. Fondo Editorial PUCP, Lima, Perú.

Arrelucea B., Maribel (2009). Replanteando la esclavitud. Estudios de etnicidad y género en Lima Borbónica. CEDET, Lima.

Barranzuela Z. Fernando (2012). Cadenas Rotas. Historia de Yapatera. Aleph Impresiones S.R.L, Lima.

BazÁn DíAz, Marissa (2013). La participación politica de los indígenas durante las Cortes de Cádiz: Lima en el ocaso del régimen español (1808-1814). SHRA. Fondo Editorial de la UNMSM, Lima, Perú.

Benavides, Juan José (2014). De milicianos del rey a soldados mexicanos. Milicias y sociedad en San Luis Potosí (17671824), CSIC, Madrid. 
Carazas, Milagros (2004). Enrique López Albújar. Esclavitud y representación del sujeto afroperuano en la Literatura. En: $\mathrm{N}^{\circ} 75,20$ de Diciembre. Lima, Perú.

Carcelén, Carlos y Horacio Maldonado (2013). La influencia social del Ejército en el Perú a finales de la época colonial. En: Prendes, Manuel y Víctor Velezmoro (eds.). Las Cortes y las crisis: ensayos en torno a la Constitución de Cádiz y su dimensión americana. UDEP-IEH, Perú.

Chiaramonte, José Carlos (1999). Ciudadanía, soberanía y representación en la génesis del Estado argentino (C. 1810-1852); p. 94-116. En: Hilda Sábato (coord.). Ciudadania politica y formación de las naciones. Fondo de Cultura Económica, México D.F.

Chiaramonti, Gabriella (2005). Ciudadanía y representación en el Perú (1808-1860): los itinerarios de la soberanía. Fondo Editorial UNMSM, Lima, Perú.

Conde, Jorge y Luis Alarcón (2014). La conversión de milicianos y guerrilleros en ciudadanos armados de la República de Colombia. En: Historia Caribe, Vol. IX, № 25; pp. 17-37, Bogotá.

Cornejo, Raúl-Estuardo (1972). "Las fuentes de 'Matalaché”. En: Cuadernos del CONUP, Diciembre; pp. 309337, Lima.

DíAz López, Zamira (2006). Los Cabildos como laboratorios del poder y la política en la génesis de la República en el suroccidente neogranadino (1808-1821). En: Memoria y Sociedad, Vol. 10, $\mathrm{N}^{\circ}$ 20, enero-junio, pp. 59-75, Pontificia Universidad Javeriana, Bogotá, Colombia.

Diez Hurtado, Alejandro (1994). Fiestas y cofradias: asociaciones religiosas e integración en la historia de la comunidad de Sechura, siglos XVII al XX. CIPCA, Piura.

Espinoza Claudio, César (2016). Los Borbones, los hacendados y la justicia real en Piura a comienzos del siglo XIX. La historia de vida de un zambo pardo y libre agobiado por sus amores, los jueces y la envidia de negros, zambos y mulatos. En: Investigaciones Sociales, $\mathrm{N}^{\circ} 36$; pp. 117-138. IIHS-Facultad de Ciencias Sociales, UNMSM, Lima, Perú.

Espinoza Claudio, César (2014). Negros esclavos y libertos en Piura. Anotaciones sobre historia política, el cimarronaje y el bandolerismo en San Miguel de Piura, Morropón, Ayabaca: 1780-1814. En: Revista de Sociología, $\mathrm{N}^{\circ}$ 24, pp. 435-482, UNMSM, Lima, Perú.

Espinoza, Waldemar (2014). Chachapoyas frente a la Independencia politica del Perú. Derrama Magisterial, Lima, Perú.

Fernández S., Javier (coord.) (2012). La aurora de la Libertad. Los primeros liberalismos en el mundo iberoamericano. Marcial Pons, Ediciones de Historia, S.A, Madrid.
Flores Galindo, Alberto (1984). Aristocracia y plebe. Lima, 1760-1830. Mosca Azul Editores, Lima, Perú.

GHidoli, María de Lourdes (2013). Estudios afrolatinoamericanos: nuevos enfoques multidisciplinarios: Actas de las Terceras Jornadas del GEALA / María de Lourdes Ghidoli y Juan Francisco Martínez Peria. - 1a ed. - Ciudad Autónoma de Buenos Aires: Ediciones del CCC Centro Cultural de la Cooperación Floreal Gorini.

https://geala.files.wordpress.com/2013/10/actas-iii-jornadas-de-estudios-afrolatinoamericanos-geala-2013.pdf. Consultado en 12.07.2015.

Guarisco, Claudia (2004). ¿Reyes o indios? Cabildos, repúblicas y autonomía en el Perú y México coloniales, 17701812. En: Revista Andina Nº 39, pp. 203-226, Cuzco.

Gutiérrez Rivas, Julissa (2013). La Constitución de Cádiz y su impacto en el ámbito social del partido de Piura. Universidad de Piura, Perú. En: Manuel Prendes Guardiola y Víctor Velezmoro Montes (eds.). Las Cortes y la crisis: ensayos en torno a la Constitución de Cádiz y su dimensión Americana. Universidad de Piura/ Instituto de Estudios Humanísticos, Tarea Asociación Gráfica Educativa, Lima.

GutiérRez Usillos, Andrés (2012). Nuevas aportaciones en torno al lienzo titulado Los mulatos de Esmeraldas. Estudio técnico, radiográfico e histórico. En: Anales del Museo de América XX, pp. 7-64.

Hernández García, Elizabeth (2008). La elite piurana y la Independencia del Perú: la lucha por la continuidad en la naciente República (1750-1824). IRA, UDEP, Lima, Perú.

KLeIn, Herbert y Ben Vinson III [1987 (2008)]. La esclavitud africana en América Latina y el Caribe. Instituto de Estudios Peruanos, Lima, Perú.

Huertas Vallejos, Lorenzo (2000). La costa peruana vista a través de Sechura: espacio, arte y tecnología. Concejo Provincial de Sechura; INC: PromPerú: Universidad Ricardo Palma, Perú.

Huertas Vallejos, Lorenzo (1995). Sechura: identidad cultural a través de los siglos. Municipalidad de Sechura, Piura, Perú.

Hunefeldt, Christine (1979). Cimarrones, bandoleros y milicianos: 1821. En: Histórica, Vol. III, Nº 2, Diciembre; pp. 71-78, PUCP, Perú.

Kuethe, Allan J. y Juan Marchena F (eds.) (2005). Soldados del Rey. El Ejército borbónico en América colonial en vísperas de la Independencia. Castelló de la Plana: Publicacions de la Universitat Jaume I. España.

Maсchi, Virgina (2012). Guerra y política en el Río de la Plata: el caso del Ejército Auxiliar del Perú (1810-1811). 
En: Anuario de la Escuela de Historia Virtual: Año 3, ${ }^{\circ}$ 3; pp. 78-96.

http://publicaciones.ffyh.unc.edu.ar/index.php/anuariohistoria. Consultado en 12.08.2016.

Maldonado, Horacio y Carlos Carcelén (2013). El ejército realista en el Perú a inicios del XIX. Las nuevas técnicas artillería e ingeniería y la represión a los alzamientos en Quito y el Alto Perú. Cuadernos de Marte, Año 4, N 5, julio-diciembre. http://publicaciones.sociales.uba. ar/index.php/cuadernosdemarte/article/viewFile/54/53 Consultado en 10.08.2016.

Marchena Juan (1992). Ejército y milicias en el mundo colonial americano. Colecciones MAPFRE, Madrid.

Martínez de Compañón, Baltazar Jaime (1785). Trujillo del Perú, tomo I. http://www.unav.edu/evento/navarramodernidad-temprana/baltasarjaime

Morales, María (2008). El espacio del esclavo negro en las haciendas del valle de Cañete, 1747-1821. En: Investigaciones Sociales, Año XII, N 21, pp. 161-183; IIHS, Facultad de Ciencias Sociales, UNMSM, Lima, Perú.

Morea, Alejandro (2015). Perfil de los oficiales del Ejército Auxiliar del Perú en el contexto revolucionario rioplatense, 1810-1820. En: HIb. Revista de Historia Iberoamericana. Vol. 8, $\mathrm{N}^{\circ}$ 2, pp. 102-131, Universia.

Moscol Urbina, Jorge (1986). Mangachería rabiosa. Edic. Piuranidad, Piura.

O'Phelan Godoy, Scarlett (2012). La elite nobiliaria y la elite ilustrada frente a la independencia del Perú. En: Illes Imperis, $\mathrm{N}^{\circ}$ 14, pp. 189-204. Universitat Pompeu Fabra, Barcelona.

O'Phelan Godoy, Scarlett (2014). La Independencia en los Andes. Una historia conectada. Fondo Editorial del Congreso del Perú, Lima.

O’Phelan Godoy, Scarlett (2012a). El Perú de Abascal: entre la Constitución de Cádiz, la Lima fidelista y la re- formulación del espacio virreinal; 196-228. En: Manuel Chust e Ivana Frasquet (eds.). La patria no se hizo sola. Las revoluciones de las Independencias Iberoamericanas. Silex Ediciones S.L., Madrid.

Ortemberg, Pablo (2014). Rituales del poder en Lima (17351828): de la monarquia a la república. Fondo Editorial, Pontificia Universidad Católica del Perú, Lima, Perú.

Ortemberg, Pablo (2012). Cádiz en Lima: de las fiestas absolutistas a las fiestas constitucionalistas en la fundación simbólica de una nueva era. En: Historia, vol. 45, $\mathrm{N}^{\circ} 2$, pp. 455-483, Santiago, Chile.

Pacheco Vélez, César (1954). Las conspiraciones del conde de la Vega del Ren. En: Revista Histórica, Tomo No 21, pp. 355-425, Lima, Perú.

Peralta Ruiz, Víctor (2012). Las juntas de gobierno hispanoamericanas (1808-1814). Reflexiones en el contexto del Bicentenario de las Independencias; pp. 311-348. En: Las independencias hispanoamericanas: Un debate para siempre. Rogelio Altez (Editor). Colección Bicentenario Bucaramanga, Colombia.

Reyes F. Alejandro (1999). Esclavitud en el valle de Cańete. Haciendas Casablanca y La Quebrada, siglo XVIII. En: Diálogos, $\mathrm{N}^{\circ}$ 1, pp. 81-94, Lima, Perú.

Sánchez Silva, Carlos y Luis A. Arrioja (2008). Los Cabildos eclesiástico y civil de Antequera ante la crisis imperial de 1808-1810. En: Signos Históricos, № 20, juniodiciembre, pp. 82-125, México D.F.

Seminario Ojeda, Miguel (1994). Historia de Sullana. Municipalidad Provincial de Sullana, Piura, Perú.

Van Young, Eric (2006). La Otra Rebelión. La lucha por la Independencia de México, 1810-1821. FCE, México.

Velásquez, María E. y Gabriela Iturralde Nieto (2012). Afrodescendientes en México. Una historia de silencio y discriminación. Consejo Nacional para Prevenir la Discriminación, México. 


\section{ANEXO DOCUMENTAL 1}

Infantería a sueldo en el puerto de Paita. Revista al mes de febrero de 1802. Lista de los individuos que se compone esta compañía en el día y fecha con expresiones de sus destinos. ${ }^{18}$

\begin{tabular}{|c|c|c|}
\hline Empleos & Nombres y Apellidos & Destino \\
\hline Capitán & José Gonzáles de la Cotera & Payta \\
\hline Teniente & Enrique O'Donovan & Payta \\
\hline Subteniente & Pedro Rolando & $\begin{array}{l}\text { Comisionado } \\
\text { en Tumbes }\end{array}$ \\
\hline Sargento & Pedro Andia & Payta \\
\hline Sargento & Manuel Hutan & Payta \\
\hline Tambor & Luis Castro & Payta \\
\hline Cabo & Thomas Bega & Payta \\
\hline Cabo & Thomas Vilela & Payta \\
\hline Cabo & Jose Ylario Michilot & Payta \\
\hline Cabo & Juan José García & Payta \\
\hline \multirow[t]{29}{*}{ Soldados } & José Vela & Payta \\
\hline & Manuel Castillo & Payta \\
\hline & Juan Jose Ruidias & Payta \\
\hline & Francisco Ruidias & Payta \\
\hline & Luis Monge & Payta \\
\hline & Fermín Quevedo & Payta \\
\hline & Agustín Aguirre & Payta \\
\hline & Manuel Carrasco & Payta \\
\hline & Balthazar de la Peña & Payta \\
\hline & Leandro Risco & Payta \\
\hline & José Guzmán & Payta \\
\hline & José Talledo & Payta \\
\hline & Rafael Farfán & Payta \\
\hline & Lorenzo Núñez & Payta \\
\hline & Juan Ruidias & Payta \\
\hline & José Soxo & Payta \\
\hline & Ramón Revolledo & Payta \\
\hline & Jacinto Vásquez & Payta \\
\hline & Ramón Pacheco & Payta \\
\hline & Domingo Sevallos & Payta \\
\hline & José Montejo & Payta \\
\hline & Manuel Salgado & Payta \\
\hline & Juan Farfán & Payta \\
\hline & José Cortes & Payta \\
\hline & Domingo Urrutia & Payta \\
\hline & Manuel Merino & Payta \\
\hline & Carlos de la Cruz & Payta \\
\hline & Juan Barrientos & Payta \\
\hline & Marino Alvarado & Payta \\
\hline
\end{tabular}

18 ARP. 1802. Lista de individuos de que se compone esta Compañía en el día, en el puerto de Paita, a 11.02.1802. Josef Gonzales de la Cotera (fs. 16-17).

\begin{tabular}{|c|c|c|}
\hline & Francisco Riveros & Payta \\
\hline & José Thalledo Moreno & Payta \\
\hline & Santiago Senen & Payta \\
\hline & Antonio María Pacheco & Payta \\
\hline & José Cruz & Payta \\
\hline & José Alvares & Payta \\
\hline & Juan José Bega & Payta \\
\hline & Manuel Farfán & Payta \\
\hline & José Ciancas & Payta \\
\hline & Marcelo Ciancas & Payta \\
\hline & Juan Manuel Velásquez & Payta \\
\hline & José Antonio Lera & Payta \\
\hline & Ignacio Guerrero & Payta \\
\hline & Julián Barrientos & Payta \\
\hline \multicolumn{3}{|l|}{$\begin{array}{l}\text { Gente de } \\
\text { Color }\end{array}$} \\
\hline $\begin{array}{l}\text { Sargento } \\
2 \text { do }\end{array}$ & Calletano? & Payta \\
\hline \multicolumn{3}{|l|}{ Soldados } \\
\hline & Andrés Aguila & Payta \\
\hline & Matías Garavito & Payta \\
\hline & Polonio Martínez & Payta \\
\hline & Nicolás Vilela & Payta \\
\hline & Juan Ramírez & Payta \\
\hline & Josélino Arica & Payta \\
\hline & Juan José Urbina & Payta \\
\hline & Francisco Rebolledo & Payta \\
\hline & Juan Morán & Payta \\
\hline & Manuel Farfán & Payta \\
\hline & Castro Ordinola & Payta \\
\hline & Lorenzo de la Luz & Payta \\
\hline & Juan Manuel Gutiérrez & Payta \\
\hline & José Escovar & Payta \\
\hline & Sebastián Escovar & Payta \\
\hline & Domingo Gutiérrez & Payta \\
\hline & Miguel Venites & Payta \\
\hline & Mauricio Ordinola & Payta \\
\hline & Lorenzo Arica & Payta \\
\hline & Domingo Castro & Payta \\
\hline & José Gabriel Ramírez & Payta \\
\hline & Salvador Quevedo & Payta \\
\hline & Casimilo Aguila & Payta \\
\hline & Balthazar Robles & Payta \\
\hline & Bicente Acosta & Payta \\
\hline
\end{tabular}

Puerto de Payta y Febrero 11 de 1802. Josef González de la Cotera 


\section{RESUMEN}

\begin{tabular}{|l|c|}
\hline Grado Militar & Número \\
\hline Capitán & 1 \\
\hline Teniente & 1 \\
\hline Subteniente & 1 \\
\hline Sargento $1^{\circ}$ & 1 \\
\hline Sargento $2^{\circ}$ & 2 \\
\hline Tambores & 2 \\
\hline Cabos & 7 \\
\hline Soldados & 68 \\
\hline TOTAL & 83 \\
\hline
\end{tabular}

\begin{tabular}{|l|l|}
\hline \multicolumn{1}{|c|}{ ALTA } & \multicolumn{1}{|c|}{ BAJA } \\
\hline $\begin{array}{l}\text { 8 de enero de 1802, en la } \\
\text { Plaza, en este teniente y } \\
\text { blancos, el soldado Ygnacio } \\
\text { Guerra. }\end{array}$ & $\begin{array}{l}\text { Enero de 1802 pide su licencia } \\
\text { absoluta Don José Carrera que está } \\
\text { enfermo: Día, mes y año pide su } \\
\text { licencia al soldado Fernando Vega } \\
\text { por enfermedad curable (f.16-17) }\end{array}$ \\
\hline $\begin{array}{l}\text { En dicho día, mes y año, se } \\
\text { asentó en la Plaza y en un } \\
\text { piquete del soldado Julián } \\
\text { Barrientos. }\end{array}$ \\
\hline
\end{tabular}

